\title{
EVALUATION OF THE PERFORMANCE OF WASTE MARBLE DUST AS A MINERAL FILLER IN HOT-MIX ASPHALT CONCRETE
}

\author{
Levy Sang ${ }^{1}$, Temitope Idowu ${ }^{1 *}$ and Victoria Okumu ${ }^{2}$ \\ ${ }^{1}$ Faculty of Engineering and the Built Environment, Technical University of Kenya, P.O Box 52428-00200, \\ Nairobi,Kenya. \\ ${ }^{2}$ Civil Engineering Department, Multimedia University of Kenya. P. O. Box 30305, Nairobi, Kenya.
}

Date received: 10/07/2020 Date accepted: 15/03/2021

*Corresponding author's email: temitope.idowu@tukenya.ac.ke

DOI: $10.33736 /$ jcest.3337.2021

\begin{abstract}
$\boldsymbol{A b s t r a c t ~ - ~ A s ~ t h e ~ c o n s t r u c t i o n ~ i n d u s t r y ~ c o n t i n u e s ~ t o ~ e v o l v e ~ g l o b a l l y , ~ t h e r e ~ i s ~ a ~ n e e d ~ t o ~ d e v e l o p ~ b e s t ~ p r a c t i c e s ~}$ geared towards achieving sustainable construction. Asphalt concrete's demand has been increasing steadily with an estimated global demand of 122.5 million tons in 2019. This is driven primarily by the growth in construction activities in developing countries as each country works towards enhancing its transportation facilities to cater to the ever-expanding population. Hence, there are needs to develop newer and more efficient means of asphalt consumption. One of such is identifying cheaper or waste materials for use in Asphalt production. This study, therefore, examined the viability of waste marble dust (WMD), an industrial waste produced during the shaping and polishing of marble blocks and also during its extraction from the mines, as a mineral filler in Hot-mix asphalt (HMA) concrete. Engineering properties such as Marshall stability and flow, Void characteristics, Indirect tensile strength and Tensile strength ratio properties were examined. It was observed that the addition of WMD steadily increased the Marshall Stability and indirect tensile strength values and lowered the voids percentages. The study's major finding is that waste marble dust is highly suitable as a mineral filler in HMA and a $3 \%$ by volume addition of WMD in HMA at $4.5 \%$ binder content produced the most optimal mix for use in road pavements.
\end{abstract}

Copyright (C) 2021 UNIMAS Publisher. This is an open-access article distributed under the Creative Commons Attribution-NonCommercial-ShareAlike 4.0 International License which permits unrestricted use, distribution, and reproduction in any medium, provided the original work is properly cited.

Keywords: Hot mix asphalt concrete, Mineral fillers, Waste marble dust, Sustainable construction, Construction waste management

\subsection{INTRODUCTION}

Asphalt concrete, a mixture of complex heterogeneous materials composed of aggregates, mastic cement, additives, and void spaces, has been an integral component of the flexible road construction process for well over a century [1]. Industry-based reports projected an upward trajectory in the global demand for asphalt and it was expected to reach 122.5 million tons by 2019 , with over $75 \%$ being used for flexible road pavements [2], [3]. The mastic cement is a paste of asphalt binder and fine aggregates that binds the graded aggregates to form asphalt concrete used for the surfacing of flexible road pavements [4]. Flexible road pavements account for the highest percentage of paved roads both in developed and developing countries. For instance, $94 \%$ of paved roads in the United States are flexible pavements [5] and in Kenya, flexible pavements account for $97 \%$ of all paved roads [6]. This implies the overall importance of flexible pavements in achieving effective road transport systems and asphaltic concrete is an integral component of these pavement types.

In the past few decades, the need for sustainability has come to the fore in several fields of endeavour including the construction industry. This gave rise to the concept of sustainable construction which is understood as "ensuring the provision of current built environment needs without compromising resources needed to meet the needs of future generations. [7]" Hence, in achieving the objectives of sustainable construction in the road pavement industry, two main approaches have been followed - 1) the development of new asphalt mixing and laying technologies and 2) the adoption of residues (wastes) and industrial by-products [8]. The adoption of waste materials that otherwise constitutes an environmental nuisance performs two roles in the achievement of sustainability. The first is it serves as a means of disposing of the waste, and hence contributing to environmental cleanup. Secondly, the productive use of waste materials offsets the costs of the conventional materials they are replacing. 
Hot-mix asphalt concrete is typically composed of the complex heterogeneous composition of aggregates, additives, and bitumen binder is also known as asphalt cement and additives. Mineral fillers are the fine mineral particles that pass through the standard sieve No 200 that are naturally present in the mineral aggregate or in cases where they are not in sufficient quantities are added to the mix. In this regard, mineral fillers form part of the aggregate skeleton of the pavement. Hence, the fillers may be obtained from the crushing of rocks at quarry sites or they may be manufactured or industrial products. Limestone powder which comprises over $70 \%$ by weight of calcium carbonate $\left(\mathrm{CaCO}_{3}\right)[9]$ is one of the most widely used mineral fillers. Other conventional filler materials include hydrated lime [10], Portland cement, slag or ash. The main functions of the mineral filler are to fill the voids in the aggregate skeleton and create a denser and more cohesive mixture, thereby increasing the overall stability of the asphalt mix and improving the adhesion between the aggregates and bitumen in Asphalt concretes [11], [12]. However, several studies have established that mineral fillers, when added to the asphaltic concrete, improve the engineering properties of the mix such as durability, skid resistance particle shape, surface area, surface texture, and other physiochemical properties.

For instance, studies by [13], [14] confirmed that fillers can modify the ageing processes of asphalt. Other studies by [15], [16] show that fillers can stiffen and/or elongate the binder, thereby affecting the fatigue and rutting properties of the asphalt. Several other studies have recorded how mineral fillers, depending on their inherent properties, significantly impacted different engineering properties of asphalt mixes and bitumen mastics [9], [17][20]. The objectives of sustainable construction were pursued in some of the studies. For instance, [18] investigated the use of biomass ashes - a renewable resource - as fillers in asphalt mixes while [17] considered the potential use of recycled fine aggregates.

Marble dust is an industrial waste produced during the shaping and polishing of marble blocks and also during its extraction from the mines. During the extraction, shaping, and polishing process, nearly $20-35 \%$ raw marble is converted into dust which is a waste [21]. Another study by [22] puts the total amount of generated marble wastes at $30-50 \%$ of the total volume of all processed blocks in marble blocks production sites. This poses an environmental problem since the dust is settled by sedimentation and left close to the processing sites. Marble dust has been observed to contain over 50\% Calcium oxide [23], and its similarity with limestone powder in terms of chemical composition [23], makes it an excellent replacement in civil engineering works. Numerous studies have, therefore, been conducted on the potential use of waste marble dust (WMD) in different civil engineering applications. In soil stabilization studies, investigations by [24] and [25] on the use of WMD for improving the properties of black cotton soil and rice husk ash stabilized expansive soil, respectively showed that significant improvements were observed in the engineering properties of the soils. These include lowering of the plastic limits, increase in shrinkage limits, lower differential free swell, and increase in the bearing capacity of the soil [24], [25]. Similarly, in a study by [26] on the use of waste marble dust as a stabilizer for the cohesive soil to be used in the construction of earth dam cores, it was observed that the presence of the waste marble dust reduced the permeability and increased the durability of the soil samples. In studies on bricks and concrete works, the investigation by [27] showed that there were improvements in the engineering properties of industrial bricks when waste granite and marble dust were incorporated. Another study by [28] proved that the incorporation of WMD can increase the freezing-thawing durability of the concrete. Several other studies on the possible application of WMD are found in literature [29]-[32]. The above utilization of waste marble dust and the positive results as observed will likely lead to an improvement in the engineering properties of the asphalt concrete. Therefore, the objectives of this study are 1) to investigate if the use of waste marble dust as a mineral filler will improve the engineering properties of hotmix asphalt and 2) and if it does, to determine the optimal mix in line with best practices for HMA in road construction. Achieving the two objectives will contribute original findings on alternative materials to conventional filler materials in HMA production, and by extension further the achievement of sustainable construction.

\subsection{MATERIALS AND METHODS}

\subsection{Materials}

\subsubsection{Aggregates}

According to [33], 90-95\% of asphalt concrete is composed of aggregates, with the remaining 5-10\% a summation of binder and air voids. The aggregates in the mix form the structural skeleton which resists deformation and transmits wheel loads to the underlying pavement layers. The aggregates should, therefore, provide enough shear strength to the asphalt mix for resisting permanent deformation. In addition to the load-bearing properties, the aggregates also determine the texture and skid resistance of the pavement surface. Hence, the aggregates should 
possess the necessary hardness, toughness, and abrasion resistance to enable the resultant mixes to withstand traffic conditions. In terms of stability, asphalt concrete (AC) types are classified as either high or low stability, also known as Type I or Type II AC, respectively [34]. This study's aggregate type and grading were focused on achieving Type I AC 0/14 wearing course. The aggregate grading, which is the process of physically blending different aggregate sizes to fit within a specific envelope, was used to determine the mix-matrix for the samples prepared as shown in Plate 1 . The Fuller curve ( 0.45 power grading chart developed by [35] was used in determining the maximum particle density before the addition of the bitumen binder. The power chart, plotted using Equation 1 was based on the assumption that the best aggregate grading for bitumen mix gives the densest particle packing.

$$
P=100(d / D)^{\mathrm{n}}
$$

Where; $\mathrm{P}$ is the total \% passing a particular sieve size; $\mathrm{d}$ is the particular sieve size opening diameter; $\mathrm{D}$ is the maximum aggregate size; $n=0.45$.

The manual [35] further details the procedure for the utilization of the 0.45 power grading chart in making adjustments to the aggregate grading during the asphalt mix design. The actual gradation of the aggregate was plotted in the same power chart and compared to the maximum density line.

\subsubsection{Bitumen Binder}

Bitumen binder, also known as asphalt cement or asphalt, is a complex mix of hydrocarbons, -dark brown to black, which may occur naturally or be obtained through petroleum refining. Large scale refining of crude oil to manufacture fuel and lubricants has made the sourcing of naturally occurring bitumen less economical. Generally, the bitumen used for road construction today is obtained by refining crude oil and the resultant product is commonly referred to as penetration grade bitumen. Some studies have also been carried out on the viability of using waste materials as additives in bitumen for asphalt production, e.g. waste paints[36], crumb rubber from waste tires [37], and High-Density Polyethylene [38], plastic [53]. The straight run bitumen of penetration grade 80/100 was used in this study

\subsubsection{Marble Dust}

Marble dust is produced as a by-product of marble processing. It mainly contains carbonate minerals mostly calcite $\left(\mathrm{CaCO}_{3}\right)$ and dolomite. The exact chemical composition of marble dust may vary depending on the location and the minerals or impurities present in the limestone during recrystallization. Typically marble dust is composed of the following major constituents; $\mathrm{Lime}(\mathrm{CaO}): 38-42 \%$, Silica $\left(\mathrm{SiO}_{2}\right): 20-25 \%$, Alumina $\left(\mathrm{Al}_{2} \mathrm{O}_{3}\right): 2-4 \%$, Oxides $(\mathrm{NaO}$ and $\mathrm{MgO}): 1.5-2.5 \%$, Carbonates $\left(\mathrm{MgCO}_{3}\right): 30-32 \%$ [23]. Further details on the physical, chemical, and morphological properties of waste marble dust, its applications and the role of its management in achieving a sustainable environment and construction are well detailed in the extensive study by [31]. Figure 1 shows samples of waste marble dust obtained from the Kenya Marble and Quarries Limited, Industrial Area, Nairobi.

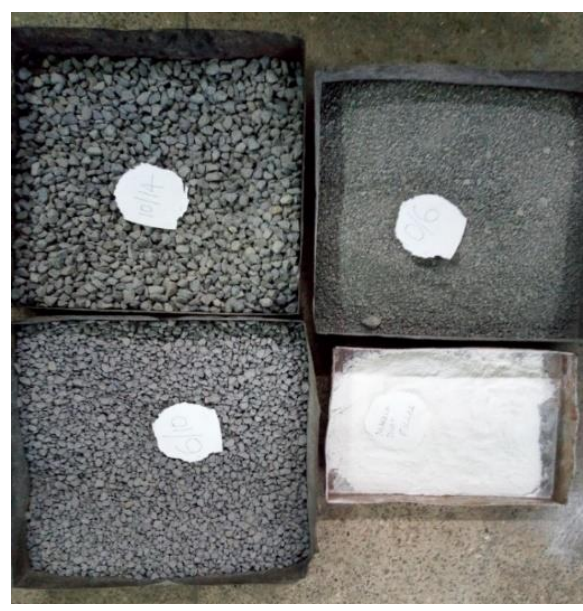

Figure 1 The graded aggregates and Waste marble dust 


\subsection{Testing Program}

\subsubsection{Aggregate and Filler Grading}

In this study, grading used to determine the Particle Size Distribution of both the aggregates and the filler was based on BS EN 1260:2013.

\section{Aggregate Grading}

The mix design involved a single size and combined grading of the aggregates. The single size grading included $0 / 6 \mathrm{~mm}, 6 / 10 \mathrm{~mm}$, and $10 / 14 \mathrm{~mm}$ aggregates while the combined grading proportioning adopted were $20 \%$ of $10 / 14 \mathrm{~mm}$ aggregates, $20 \%$ of $6 / 10 \mathrm{~mm}$ aggregates, and $60 \%$ of $0 / 6 \mathrm{~mm}$ aggregates. The summary of the aggregate grading for the HMA is presented in Table 1 and the resulting grading curve is presented in Figure 1.

Table 1. Grading Data for the aggregates (According to the Kenya Road Design Manual)

\begin{tabular}{llllllll}
\hline Agg size & $\mathbf{1 0 / 1 4 m m}$ & $\mathbf{6 / 1 0 m m}$ & $\mathbf{0 / 6 m m}$ & $\mathbf{0 / 6 m m}$ & \multicolumn{3}{c}{ GRADING } \\
\cline { 2 - 9 } & \multicolumn{3}{c}{ PROPORTIONS } & Theoretical & Actual grading & \multicolumn{2}{l}{$\begin{array}{l}\text { Standard } \\
\text { specification }\end{array}$} \\
\hline Sieve(mm) & $\mathbf{2 0}$ & $\mathbf{2 0}$ & $\mathbf{6 0}$ & grading & & $\mathbf{m i n}$ & max \\
$\mathbf{2 0}$ & $\mathbf{1 0 0}$ & $\mathbf{1 0 0}$ & 100 & $\mathbf{1 0 0}$ & $\mathbf{1 0 0}$ & $\mathbf{1 0 0}$ & \\
$\mathbf{1 4}$ & 94 & 100 & 100 & $\mathbf{9 9}$ & $\mathbf{9 8}$ & $\mathbf{9 0}$ & $\mathbf{1 0 0}$ \\
$\mathbf{1 0}$ & 2.4 & 82 & 100.0 & $\mathbf{7 7}$ & $\mathbf{7 8}$ & $\mathbf{7 0}$ & $\mathbf{9 0}$ \\
6.3 & 0.0 & 19.8 & 100.0 & $\mathbf{6 4}$ & $\mathbf{6 5}$ & $\mathbf{5 5}$ & $\mathbf{7 5}$ \\
$\mathbf{4}$ & 0.0 & 0.0 & 96.0 & $\mathbf{5 8}$ & $\mathbf{5 8}$ & $\mathbf{4 5}$ & $\mathbf{6 3}$ \\
$\mathbf{2}$ & 0.0 & 0.0 & 64.0 & $\mathbf{3 8}$ & $\mathbf{3 8}$ & $\mathbf{3 3}$ & $\mathbf{4 8}$ \\
1 & 0.0 & 0.0 & 39.0 & $\mathbf{2 3}$ & $\mathbf{2 4}$ & $\mathbf{2 3}$ & $\mathbf{3 8}$ \\
0.425 & 0.0 & 0.0 & 23.0 & $\mathbf{1 4}$ & $\mathbf{1 4}$ & $\mathbf{1 4}$ & $\mathbf{2 5}$ \\
$\mathbf{0 . 3}$ & 0.0 & 0.0 & 19.0 & $\mathbf{1 1}$ & $\mathbf{1 1}$ & $\mathbf{1 2}$ & $\mathbf{2 2}$ \\
0.15 & 0.0 & 0.0 & 13.0 & $\mathbf{8}$ & $\mathbf{8}$ & $\mathbf{8}$ & $\mathbf{1 6}$ \\
$\mathbf{0 . 0 7 5}$ & 0.0 & 0.0 & 9.5 & $\mathbf{6}$ & $\mathbf{6}$ & $\mathbf{5}$ & $\mathbf{1 0}$ \\
\hline
\end{tabular}

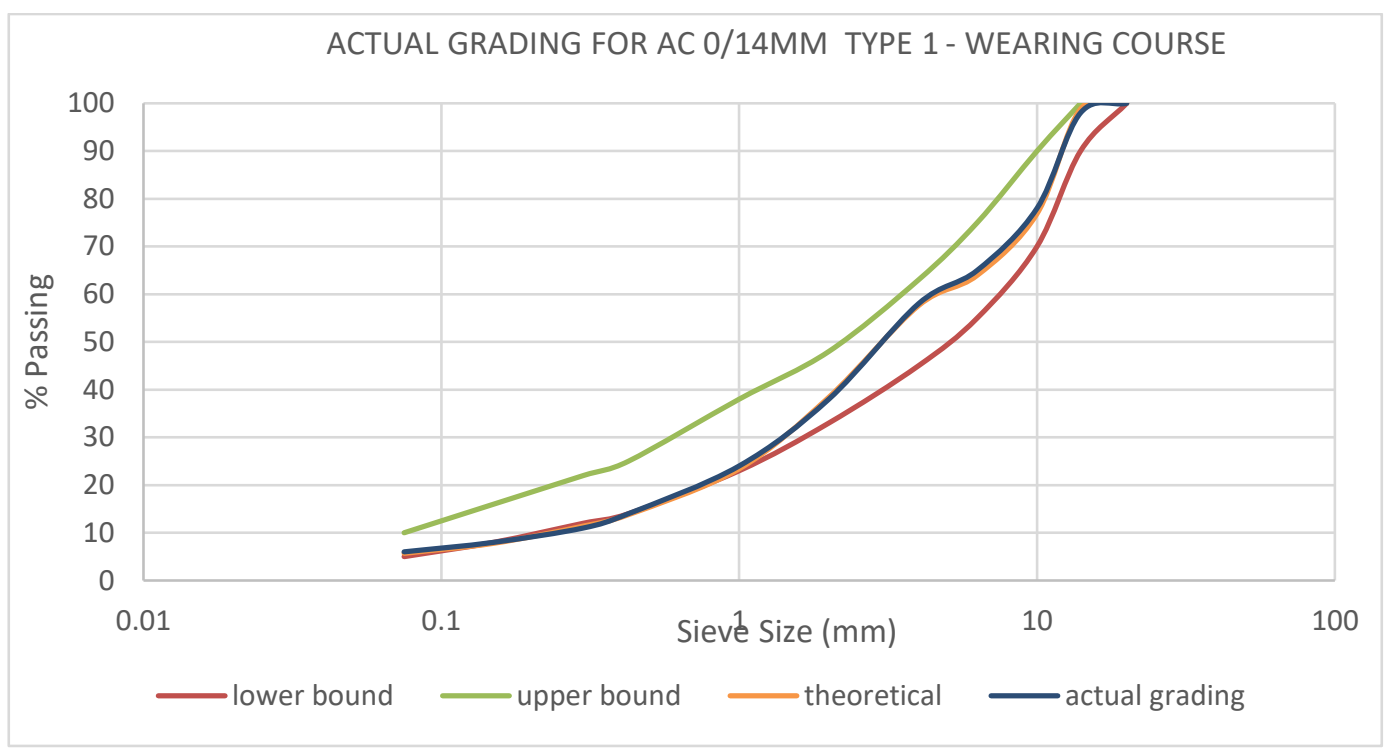

Figure 2 Grading curve for the Type 1 wearing course asphalt concrete.

From the grading curve plotted in Figure 2, the actual grading curve lied within the upper and lower bound envelope, but slightly closer to the lower bound with aggregates passing sieve $1 \mathrm{~mm}$ hence the need to improve it with a filler. When aggregates are well fitted within the curve, the friction at many points are higher and the mix voids are relatively lower in comparison to aggregates whose curves lie outside the envelope.

\section{Filler Grading}


Filler grading was done on waste marble dust to determine the suitability of the use as a mineral filler. The results for the filler grading are as shown in Table 2 and the filler grading curve in Figure 2.

Table 2 Filler grading (According to the Kenya Road Design Manual)

\begin{tabular}{cccccc}
\hline Sieve Size & Mass Retained & Mass Passing & \% Passing & MIN & MAX \\
\hline 600 & 0 & 760 & 100 & 100 & 100 \\
425 & 0 & 760 & 100 & 100 & 100 \\
300 & 0 & 760 & 100 & 95 & 100 \\
150 & 58 & 702 & 92 & 90 & 100 \\
75 & 168 & 534 & 70 & 70 & 100 \\
\hline
\end{tabular}

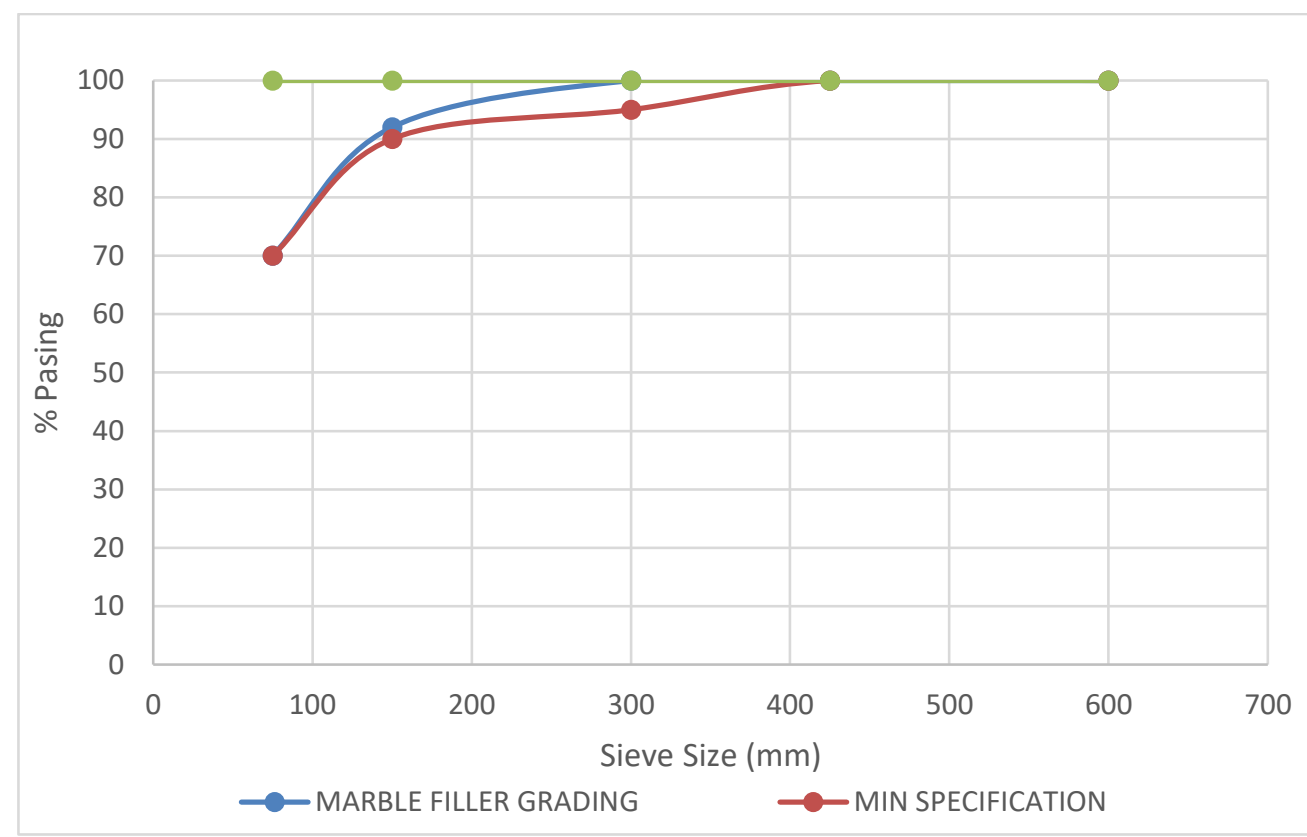

Figure 3. Filler Grading curve

Filler grading was done on waste marble dust to determine the suitability of the use as a mineral filler in asphalt concrete mixes. The confirmatory test from the grading curve supports the use of waste marble dust as a filler since the grading curve fits within the minimum and maximum limits as shown in Figure 3.

Finally, the initial binder content for the mix was determined using Equation 2 [39].

$$
D B C=0.035 a+0.04 b+K_{c}+F
$$

Where; $\mathrm{DBC}=$ Approximate Design Bitumen Content percent by total weight of mix, $\mathrm{A}=\%$ of mineral aggregate retained on the $2.36 \mathrm{~mm}$ sieve, $\mathrm{B}=\%$ of mineral aggregate passing the $2.36 \mathrm{~mm}$ sieve and retained on the $0.075 \mathrm{~mm}$ sieve, $\mathrm{C}=\%$ of mineral aggregate passing the $0.075 \mathrm{~mm}$ sieve, $\mathrm{K}=0.15$ for $11-15 \%$ passing the $0.075 \mathrm{~mm}$ sieve, $=$ 0.18 for $6-10 \%$ passing the $0.075 \mathrm{~mm}$ sieve, $=0.20$ for $5 \%$ passing the $0.075 \mathrm{~mm}$ sieve, $\mathrm{F}=0-2 \%$ Based on absorption of bitumen. In the absence of other data, a value of 0.7 is suggested [39].

\subsubsection{Confirmatory Tests}

Confirmatory tests according to the Standards were conducted to determine the suitability of the mechanical properties of aggregates, bitumen grade, and the use of waste marble dust as a filler. They include; Grading, Flakiness Index, Los Angeles Abrasion, Aggregate Crushing Value, Penetration on Bitumen as shown in Table 3. 
Table 3 Confirmatory Tests

\begin{tabular}{llr}
\hline Confirmatory Test & Objective & Standards and Codes Code used \\
\hline Grading & $\begin{array}{l}\text { To determine the Particle Size Distribution of the } \\
\text { aggregates and the filler (grading) }\end{array}$ & BS EN 13043:2015 [40] \\
Flakiness Index & To determine the flatness of an aggregate sample & BS EN 933-3: 2012 [41] \\
LAA & $\begin{array}{l}\text { To determine the hardness of aggregates when } \\
\text { exposed to wearing action. }\end{array}$ & BS EN 1097-2: 2010 [42] \\
ACV & $\begin{array}{l}\text { To determine the relative resistance of aggregates to } \\
\text { crushing on the application under a gradually applied }\end{array}$ & BS EN 1097-2: 2010 [42] \\
& $\begin{array}{l}\text { load. } \\
\text { To determine the consistency of the bitumen and its }\end{array}$ & BS EN 1426:2015 [44] \\
Penetration on Bitumen & & \\
\hline
\end{tabular}

The summary of the outcomes of each confirmatory test conducted on the materials is represented by Tables 4 .

Table 4 Confirmatory Tests Results

\begin{tabular}{lcc}
\hline TEST & VALUE & Specifications according to the standards \\
\hline Flakiness Index (FI) & 16.9 & $\operatorname{Max} 25$ \\
Los Angeles Abrasion (LAA) & 28 & $\operatorname{Max} 35$ \\
Aggregate Crushing Value (ACV) & 25.7 & $\operatorname{Max} 30$ \\
Penetration on Bitumen & 83.5 & $80-100$ \\
\hline
\end{tabular}

\subsubsection{Marshall Stability and Flow}

Asphalt concrete requires sufficient strength and stability to withstand and transfer traffic loads from the surface. This is captured by the Marshall stability properties of the AC. For Type I AC, the Marshall stability ranges from $8000 \mathrm{~N}$ to $19,000 \mathrm{~N}$ [34]. In this study, the Marshall Stability and Flow tests were based on the BS EN 1269734:2012 [45]. Marshall Stability is a measure of permanent deformation resistance by the asphalt concrete. The test is used for asphalt mixes containing bitumen where the maximum aggregate size is $25.4 \mathrm{~mm}$ or less. Asphalt specimens were loaded on their cylindrical side-edges with a Marshall loading head at a specified loading rate and temperature. The resistance against the plastic flow was measured. Marshall Flow is the amount of deformation that occurs under maximum load.

\subsubsection{Determination of voids percentage}

The determination of the volumetric properties of the compacted specimen from which the voids percentage was obtained was based on the BS EN 12697-8:2018 [46]. The volumetric parameters obtained include the Dry bulk density, Air voids $\mathrm{V}_{\mathrm{A}}$, Voids in mineral aggregate (VMA), and Voids filled with bitumen (VFB).

The Bulk Densities of the samples were determined using the buoyancy method where the volume of a sample was estimated based on the volume of water it displaces when immersed in water. The estimations are represented by equations 3 and 4 where the volume was estimated using equation 3 and the bulk density using equation 4 .

$$
\text { Volume }=S S D-\text { weight in water }
$$

Where; SSD is the saturated surface dry condition of the samples after weighing in water.

The bulk density was then calculated as shown in Equation 4.

$$
\text { Bulk Density }=\frac{\text { Weight in air }}{S S D}
$$

The Air Voids $\left(\mathrm{V}_{\mathrm{al}}\right)$ are the tiny spaces between the skeletons formed by the coarse and fine aggregates in the presence of the bitumen. The air voids, to some extent, influence the aggregate interlocking characteristics and compaction of the mix [47]. The percentage volume of air voids in the compacted asphalt mix was determined using Equation 5. 


$$
\text { Voids, } V_{a}=\frac{G_{m m}-G_{m b}}{G_{m m}} * 100
$$

Where; $G_{m m}$ is the measured maximum specific gravity of uncompacted asphalt mix, $G_{m b}$ is the measured bulk specific gravity of the compacted asphalt mix

The Voids in mineral aggregate (VMA), which is the inter-granular void space between aggregate particles in a compacted mixture that includes the air voids and the effective asphalt content expressed as a $\%$ of the total volume. The VMA was calculated based on the bulk specific gravity of the combined aggregate and is expressed as a $\%$ of the bulk volume of the compacted asphalt mixture as shown in Equation 6.

$$
V M A=100-\frac{G_{m b}\left(P_{s}\right)}{G_{s b}}
$$

Where; $\mathrm{G}_{\mathrm{mb}}$ is the measured bulk specific gravity of the compacted asphalt mixture, $\mathrm{P}_{\mathrm{s}}$ is the \% by weight of the total amount of aggregate in the mixture, $\mathrm{G}_{\mathrm{sb}}$ is the bulk specific gravity of the combined aggregate.

The Voids filled with bitumen (VFB) are the void spaces found between the aggregates in the compacted AC mixture containing the bitumen binder. It is expressed as a percentage of the VMA in the presence of a bitumen binder [48].

\subsubsection{Indirect Tensile Strength and Tensile Strength Ratio}

The Indirect Tensile Strength (ITS) helps determine the tensile characteristics of the asphalt mix which can be further related to the cracking behaviour of the final pavement. Higher tensile strength is indicative of a higher resistance of the pavement to cracking. Conversely, the tensile strength ratio (TSR) indicates the moisture sensitivity of the samples. In this study, the experimental setup for the ITS and TSR of the HMA mix was based on BS EN 12697-23:2017 [49]. Details of the test procedures are outlined in the standard [49]. On the final analysis, the Indirect Tensile Strength (ITS) was calculated as shown in equation 7.

$$
I T S=\frac{2 P}{\pi t D}
$$

Where; ITS = Indirect Tensile Strength $\left(\mathrm{N} / \mathrm{mm}^{2}\right), \mathrm{P}=$ Maximum load applied to specimen in $\mathrm{N}$, $\mathrm{t}=$ Specimen thickness $(\mathrm{mm})$ and $\mathrm{D}=$ Specimen diameter $(\mathrm{mm})$.

The Tensile Strength Ratio (TSR) is the ratio of the Indirect Tensile Strength of soaked samples to the dry samples. The Asphalt Institute recommends that the Tensile Strength Ratio (TSR) for asphalt mixes be equal to or greater than $0.7[50]$.

\section{RESULTS AND DISCUSSIONS}

Triplicate samples of the HMA samples were tested for WMD filler increments of 0,1\%,3\% and 5\% at binder contents of $4 \%, 4.5 \%, 5 \%, 5.5 \%$ and $6 \%$. The results of the Marshall Stability and flow, Voids properties, and strength are discussed in this section.

\subsection{Effects of WMD on the Marshall Stability}

The summary of the Marshall Stability values obtained under the varying percentages of WMD fillers and bitumen binder contents (BC) are presented in Table 5. It can be observed that the Marshall Stability generally increases with the increasing addition of binder up to a certain point and declines beyond that point for each WMD percentage. These points are the optimal binder percentages for that particular filler content. A glance at the trends along the columns in Table 5 shows that the Marshall Stability values increased with an increase in the WMD content in the HMA mix. Figure 4 illustrates the increasing trend with the blue line which represents 5\% WMD mineral filler in the mix recording the relatively highest values across each binder content and conversely, the purple line which represents an absence of WMD in the mix (neat sample), recorded the lowest values. 
Table 5 Marshall Stability Values

\begin{tabular}{|c|c|c|c|c|c|}
\hline \multirow{2}{*}{$\underset{\substack{\text { WMD Filler } \\
(\%)}}{\text { Binder }}$} & 4 & 4.5 & 5 & 5.5 & 6 \\
\hline & \multicolumn{5}{|c|}{ Marshall Stability values (N) } \\
\hline 0 (No filler) & 7561 & 7421 & 8003 & 9179 & 8162 \\
\hline 1 & 9264 & 9497 & 9304 & 9687 & 9130 \\
\hline 3 & 8611 & 10835 & 10247 & 9383 & 8533 \\
\hline 5 & 13342 & 14457 & 13301 & 10988 & 9887 \\
\hline
\end{tabular}

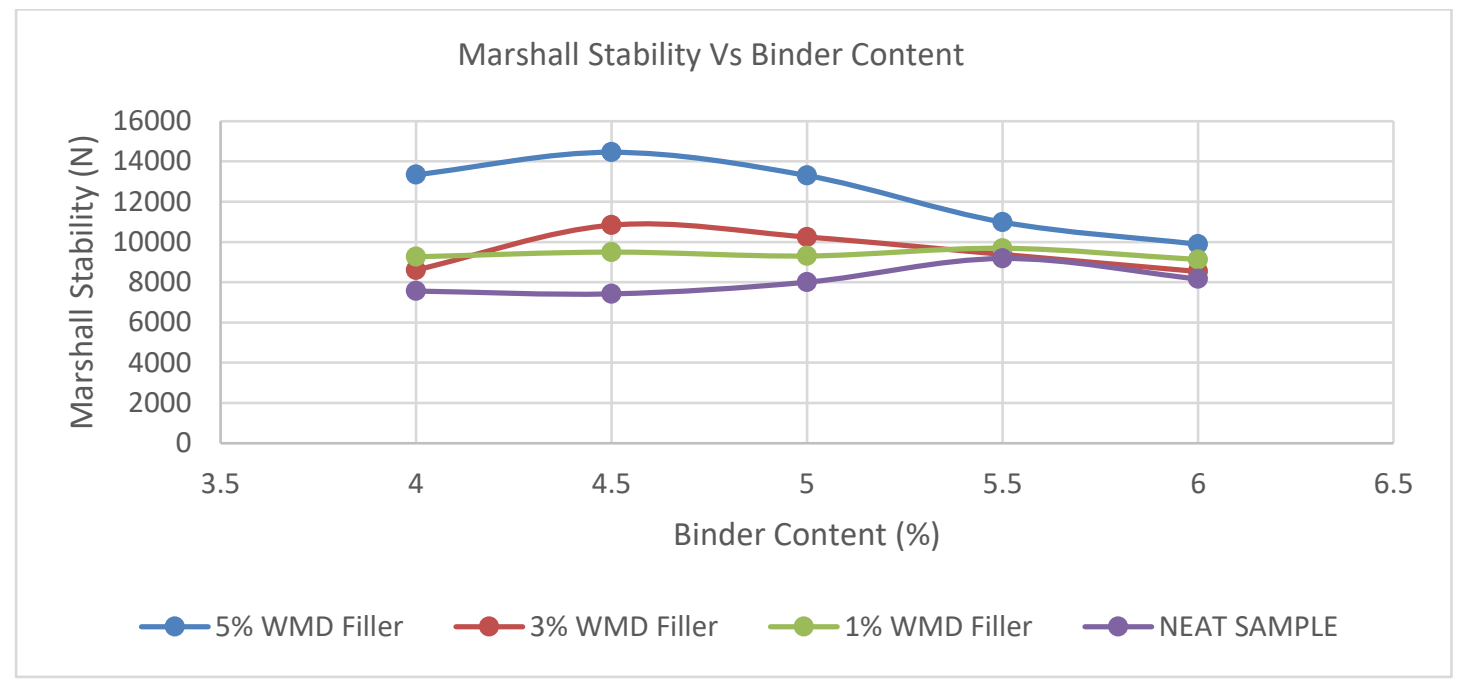

Figure 4 Marshall Stability vs Binder Content

The Marshall stability at optimum binder content is $9179 \mathrm{~N}$ at $5.5 \% \mathrm{BC}$ for neat sample, $9687 \mathrm{~N}$ at $5.5 \%$ B.C for $1 \%$ waste marble dust filler, $10835 \mathrm{~N}$ at $4.5 \% \mathrm{BC}$ for $3 \%$ WMD Filler, $14457 \mathrm{~N}$ at $4.5 \%$ B.C for $5 \%$ WMD filler as indicated in green in Table 5. It should be noted that extremely high values of Marshall Stability imply that the asphalt concrete will be too stiff, hence may be susceptible to failures associated with poor workability. On the other hand, extremely low values of the Marshall Stability imply low pavement durability under traffic loads. In this study, the highest value $(14,457 \mathrm{~N})$ was observed at $5 \%$ filler and $4.5 \% \mathrm{BC}$ while the lowest value of $7421 \mathrm{~N}$ was observed when no WMD was added to the mix at $4.5 \%$ BC. These trends observed in the marshal stability values are similar to that of a related study where waste marble was used as a filler in Dense bituminous macadam (DBM) and the highest values were observed to be $12.95 \mathrm{KN}$ obtained for a $4 \%$ filler at $5.5 \%$ bitumen content [48]. In comparison to conventional filler materials, the maximum Marshall stability values in an HMA mix were obtained at $2.5 \%$ for limestone and 3.0\% for cement dust in a study by [51]. Based on the guidelines, the minimum standard Marshall stability value is $7500 \mathrm{~N}$ [52]. As seen in Table 1, for a neat sample to meet this threshold, more bitumen blinder will be required above $4.5 \%$ but introducing the WMD mineral filler drastically raises the values above the threshold at any $\mathrm{BC}$ percentage, the optimal being at $4.5 \%$.

\subsection{Effects of WMD on the Marshall Flow}

Asphalt concrete with lower values of Marshall flow tends to fail due to disintegration, while higher values mean that the workability is also greatly reduced if they exceed the given limits. As per the specification, the Marshall flow should range between 2 and 4mm [30]. The Marshall Flow values obtained from this study's samples are as tabulated in Table 6. From the Table, it can be observed that there was a general increase in Marshall Flow with an increasing percentage of the filler for each binder content. Across the table, for the same \% WMD filler, there was a gradual increase in the flow values up to a certain point before decreasing. However, with exceptions of the samples with extremely high binder content $(6 \%)$ and no filler which recorded a value of $1.81(<2)$ and the samples with high WMD filler content (5\%) coupled with relatively high BC, thereby recording values of 4.40 and 4.09 $(>4)$, over $80 \%$ of the samples fell within the range stipulated in the standards and are highlighted in green. 
Table 6 Marshall Flow values

\begin{tabular}{c|ccccc}
\hline \multirow{2}{*}{$\begin{array}{c}\text { Binder } \\
\text { WMD Filler } \\
(\boldsymbol{\%})\end{array}$} & $\mathbf{4}$ & $\mathbf{4 . 5}$ & $\mathbf{5}$ & $\mathbf{5 . 5}$ & $\mathbf{6}$ \\
\hline $\mathbf{0}$ (No filler) & & & Marshall Flow values (mm) & 2.60 & 2.57 \\
$\mathbf{1}$ & 2.10 & 2.23 & 2.59 & 2.92 & 2.89 \\
$\mathbf{3}$ & 2.59 & 2.43 & 2.72 & 3.17 & 3.96 \\
\hline $\mathbf{5}$ & 3.36 & 3.86 & 3.45 & 4.09 & \\
\hline
\end{tabular}

Figure 5 further illustrates how the lower curve of the neat sample has the least flow within the range of $1.81-3$ $\mathrm{mm}$ except for the $6 \%$ binder content where the flow drops to $1.81 \mathrm{~mm}$. The $1 \%$ and $3 \%$ waste marble dust filler seem to produce the best flow values across all binder contents.

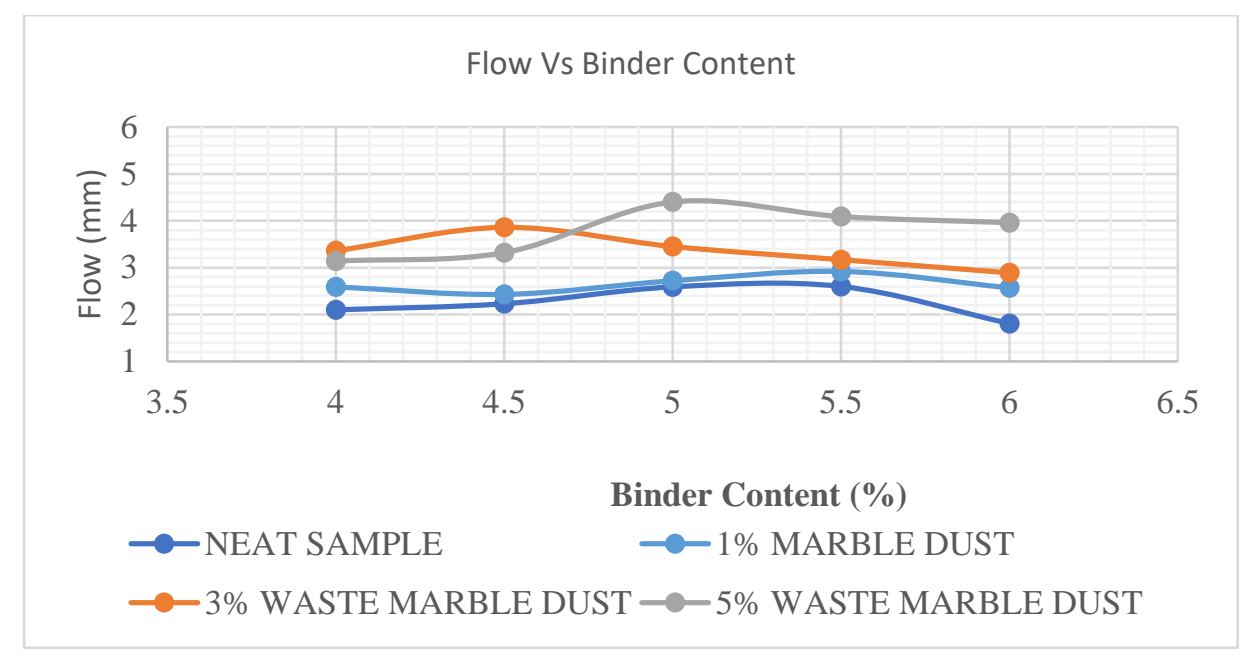

Figure 5 Flow Vs Binder Content

\subsection{Effects of WMD on the percentage $\mathrm{V}_{\mathrm{a}}$, VMA and VFB}

The percentage of voids is an important element in asphalt concrete. The resulting calculations show that the measured specific gravities and bulk densities of the samples varied from 2.41 to 2.49 and $2.19 \mathrm{~g} / \mathrm{cm}^{3}$ to $2.29 \mathrm{~g} / \mathrm{cm}^{3}$, respectively. The summary of the values of the percentage voids, voids in mineral aggregates, and voids filled with bitumen are given in Table 7 and the plot of the relationship between the binder content and these variables for each addition of WMD are given in Figure 5.

Table 7 Percentages Voids properties

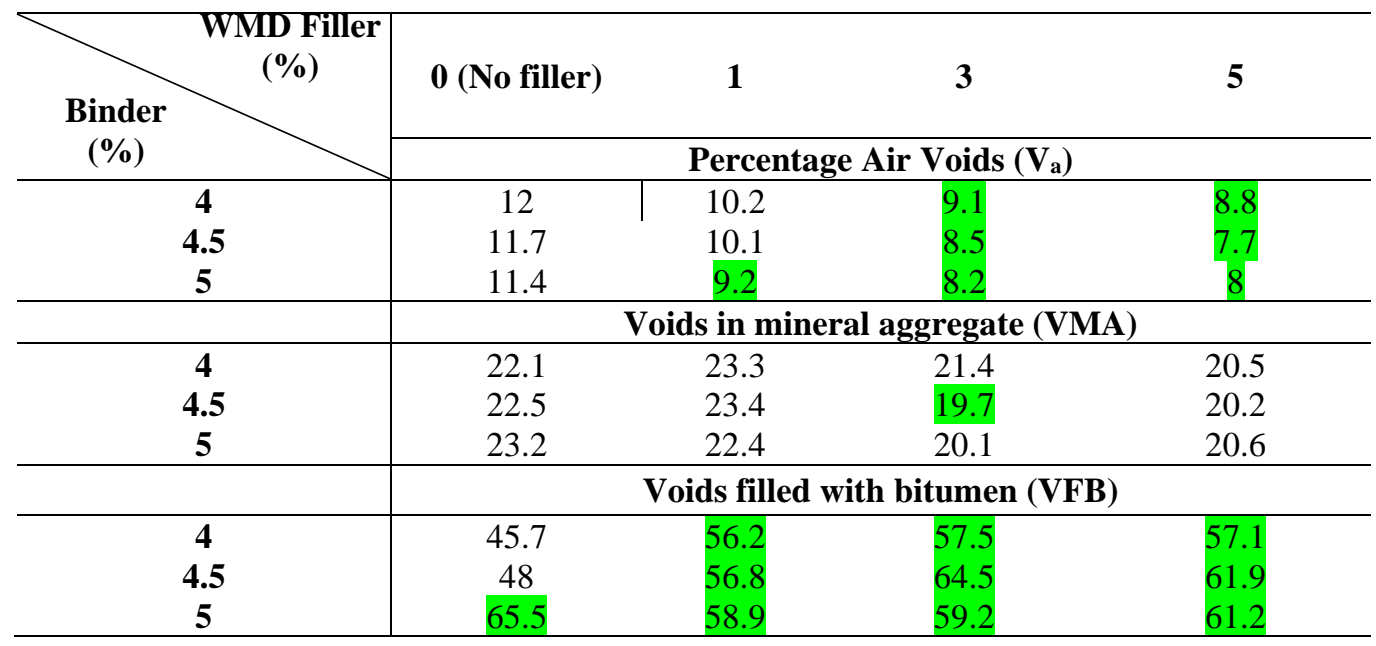


Voids \% Vs Binder Content

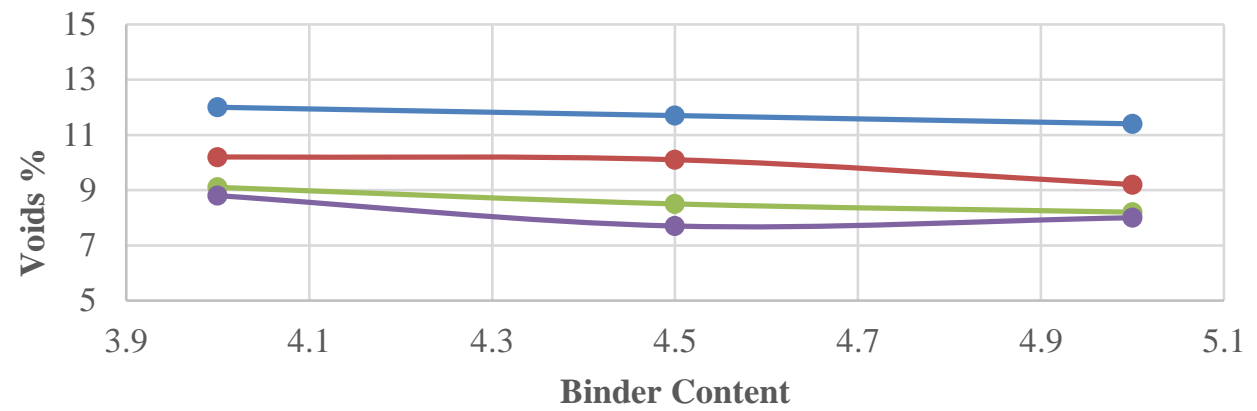

$\longrightarrow$ NEAT SAMPLE $\longrightarrow 1 \%$ WASTE MARBLE FILLER

$-3 \%$ WASTE MARBLE FILLER $-5 \%$ WASTE MARBLE FILLER

Figure 6a A plot of Binder Content against the Voids \% $\left(\mathrm{V}_{\mathrm{a}}\right)$

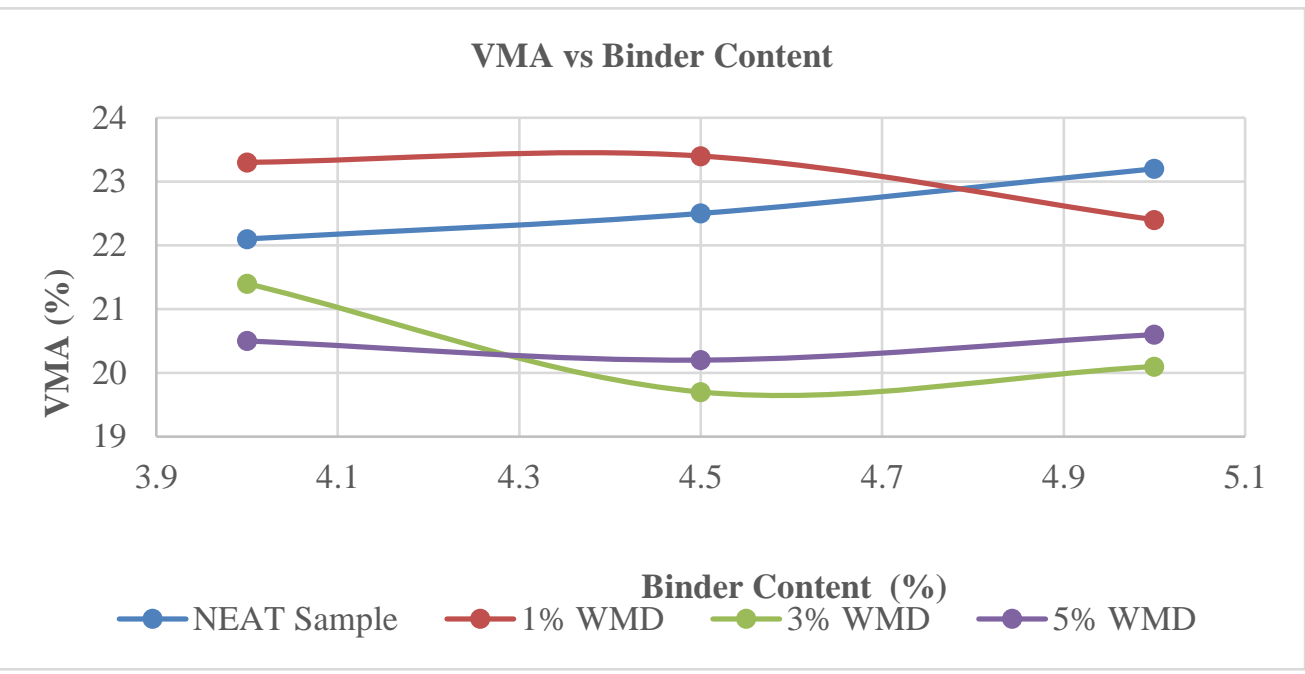

Figure 6b A plot of Binder Content against the Voids in mineral aggregates (VMA)

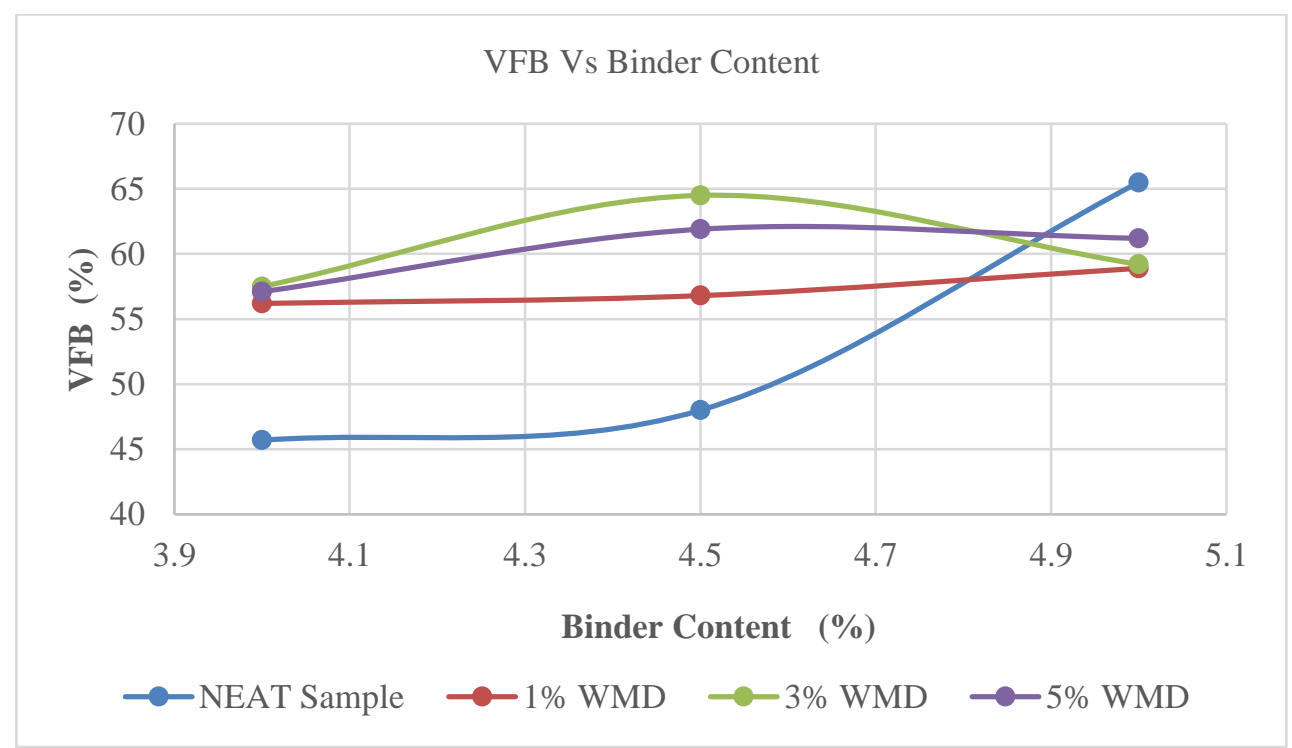

Figure 6c A plot of Binder Content against the Voids filled with bitumen (VFB) 
The voids percentage allowed for asphalt concrete mixes is in the range of $5-10 \%$ [30]. From Figure 6a, the voids for the neat sample are above $10 \%$ for the different binder percentages. The air voids percentage with $1 \%$ filler reduces to a maximum of 10.2 at $4 \%$ binder content, 10.1 at $4.5 \%$ binder content, and 9.2 at $5 \%$ binder content. With $3 \%$ filler, the range of the air voids is $8.2 \%$ at $5 \%$ binder content, 8.5 at $4.5 \%$ binder content, and to a maximum of $9.1 \%$ at $4 \%$ binder content which is within the range. The $5 \%$ filler also meets the specification since the range is 7.7 with $4.5 \%$ binder, 8 at $5 \%$ binder, and 8.8 at $4 \%$ binder. Air voids are important during the rolling of the asphalt concrete and also allows for differential temperature variations as can be experienced in the field. Higher values of the percentage voids beyond the maximum allowed value increase the susceptibility to moisture damage of the pavement. Lower values below the given specifications, on the other hand, reduces the workability of the asphalt concrete during rolling hence the required compaction levels might not be achieved.

There are no specific values for the VMA and VFB. However, from previous studies, VMA values should generally be low (20\% or less) while the VFB ranges between 50 and $70 \%$. As observed in Figures $6 \mathrm{~b}$ and $6 \mathrm{c}$, the addition of the WMD mineral had an inconsistent effect on the VMA and VFB values at varying percentages of binder contents as observed. Nevertheless, it can be observed that the increasing addition of WMD mineral filler progressively lowered the VMA values from $>20 \%$ to $<20 \%$ especially at $5 \%$ BC where the VMA values from $23.2 \%$ to $20.6 \%$ at $0 \%$ and $5 \%$, respectively. The addition of the WMD binder at $1 \%, 3 \%$, and $5 \%$ placed the VFD values within the 50-70\% range for all values BC (Figure 5c).

\subsection{Effects of WMD on the Indirect Tensile Strength (ITS) and Tensile Strength Ratio (TSR)}

The Indirect Tensile Strength is a direct indicator of the moisture sensitivity of the mix. Therefore, per the above results, it can be seen that the strength characteristics of the treated mixes remain higher than those of the untreated mix. It can also be observed that the incorporation of the mineral filler improved the ITS of the HMA concrete. The Tensile Strength Ratio (TSR) for Asphalt Concrete should be greater than or equal to 0.7 [43]. The Tensile Strength Ratio of the treated mixes were all above the 0.7 thresholds, and hence within the required limit. This implies that the addition of WMD mineral filler into the HMA will not increase the susceptibility of the mix to damage due to moisture.

Table 8 Indirect Tensile Strength Values

\begin{tabular}{l|cccc}
\hline \multirow{2}{*}{ Waste marble filler \% } & $\mathbf{0}$ & $\mathbf{1}$ & $\mathbf{3}$ \\
\cline { 2 - 4 } & \multicolumn{4}{|c}{ Indirect Tensile Strength $\left(\mathbf{N} / \mathbf{m m}^{\mathbf{2}}\right)$} \\
\hline SOAKED & 46.4 & 46.8 & 47.1 & 48.5 \\
UNSOAKED & 52.24 & 52.5 & 53.14 & 54.2 \\
\hline TSR & 0.89 & 0.89 & 0.88 & 0.9 \\
\hline
\end{tabular}

Figure 7 is a plot of the Filler percentages against the indirect tensile strength values for both the soaked and unsoaked samples. The Figure illustrates that besides the fact that the ITS values for the unsoaked samples were generally higher, the addition of WMD as a mineral filler in HMA brings a corresponding increase in the ITS.

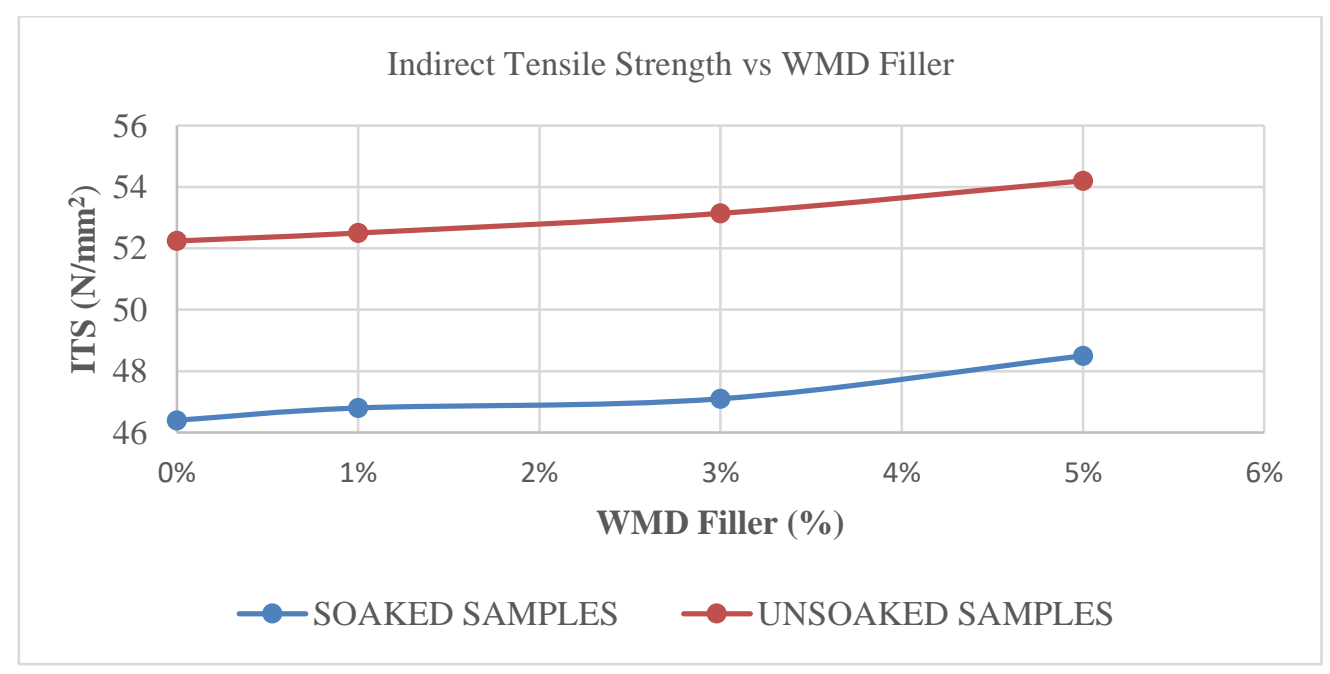

Figure 7 ITS Vs Filler (\%) 


\subsection{CONCLUSION}

In the bid to advance the objectives of sustainable construction, there is the need to develop ever new ways of utilizing materials that would otherwise constitute environmental waste that poses challenges to management and disposal. In this study, waste marble dust - a waste that usually amounts to $30-50 \%$ of the total volume of all processed blocks in the marble blocks production industry - was tested for its viability as a mineral filler in HotMix-Asphalt concrete. The findings of the study show that Waste marble dust filler increases the Marshall Stability from $9179 \mathrm{~N}$ at $5.5 \%$ Binder content for the neat sample to $10,835 \mathrm{~N}$ when $3 \%$ of Waste marble dust filler is used at $4.5 \%$ binder content. The flow of Asphalt concrete increased from $2.6 \mathrm{~mm}$ for the neat sample at $5.5 \%$ Binder content to $3.86 \mathrm{~mm}$ when $3 \%$ of waste marble dust filler is used at $4.5 \%$ binder content. The voids percentage reduced from $11.7 \%$ for the neat sample to $8.5 \%$ when $3 \%$ of waste marble dust is used as a filler at $4.5 \%$ binder content. This is a $27 \%$ reduction in $\mathrm{V}_{\mathrm{a}}$. Furthermore, it was observed that the increasing addition of WMD mineral filler progressively lowered the VMA values from $>20 \%$ to $<20 \%$. The addition of the WMD binder at $1 \%, 3 \%$, and 5\% placed the VFD values within the 50-70\% range for all values BC. The Indirect Tensile Strength of HMA increased from $52.24 \mathrm{~N} / \mathrm{mm}^{2}$ (neat sample value) to $53.14 \mathrm{~N} / \mathrm{mm}^{2}$ when $3 \%$ of WMD is used for the unsoaked samples and $46.4 \mathrm{~N} / \mathrm{mm}^{2}$ (neat sample value) to $47.1 \mathrm{~N} / \mathrm{mm}^{2}$ when $3 \%$ waste marble dust is used as a filler for the soaked samples. By observing Tables 5-7, it can be observed that the only combination that meets the thresholds according to the specifications for the Marshall Stability and flow, Va, VMA, and VFD is the 3\% by volume addition of the waste marble dust in the HMA at $4.5 \%$ binder content. At $4.5 \% \mathrm{BC}$, the addition of WMD at $1 \%$, $3 \%$ and $5 \%$ increased the Marshall stability by $28 \%, 46 \%$ and $95 \%$, respectively. Hence, it can be concluded that waste marble dust is not only a suitable material, but the optimal percentage is $3 \%$ by volume of the aggregate in a Hot-mix asphalt at $4.5 \%$ binder content.

\section{Conflict of Interests}

The authors declare that there is no conflict of interests regarding the publication of this paper.

\section{Acknowledgement}

The authors acknowledge the Materials Testing and Research Division Headquarters in Nairobi for making their laboratories available for carrying out the various tests, the Kenya Marble and Quarries Limited, Nairobi for granting us access to their site for obtaining the waste marble dust. Finally. The authors acknowledge the academic and technical staff of the Technical University of Kenya, for their guidance and support all through the entire research.

\section{References}

[1] P. Pawel, H. Baoshan, S. Xiang, and G. Hongren, 2019. Investigation into Locking Point of Asphalt Mixtures Utilizing Superpave and Marshall Compactors. J. Mater. Civ. Eng. (31)9: 4019188. https://doi.org/10.1061/(ASCE)MT.19435533.0002839

[2] ARI Aggregate Research, 2015. World demand for asphalt set to grow. , Cleveland, OH.

[3] The Freedonia Group, 2015. Asphalt: US Industry Study with Forecasts for 2019 \& 2024. , Cleveland, OH, USA.

[4] Y. Dai, Q., \& You, 2007. Prediction of creep stiffness of asphalt mixture with micromechanical finite-element and discrete-element models. J. Eng. Mech. (133)2: https://doi.org/10.1061/(ASCE)0733-9399(2007)133:2(163)

[5] Y. Qiao, A. R. Dawson, T. Parry, G. Flintsch, and W. Wang, 2020. Flexible Pavements and Climate Change : A Comprehensive Review and Implications. Sustainability (12)1057: 1-21. https://doi.org/10.3390/su12031057

[6] F. K. Kibukwo, 2013. Cost comparison of concrete versus flexible pavement designs for steep to rolling sections along A104 road (Nakuru- Eldoret. Univ. Nairobi Dep. Civ. Constr. Eng. .

[7] A.-M. Mahamadu, K. Baffour Awuah, and C. A. Booth, 2016. 2 - Principles of sustainability and life-cycle analysis. , in Woodhead Publishing Series in Civil and Structural Engineering, J. M. B. T.-S. of C. M. (Second E. Khatib, Ed. Woodhead Publishing, 13-31. https://doi.org/10.1016/B978-0-08-100370-1.00002-0

[8] I. Pe, L. Caaman, B. Go, and N. Pe, 2018. Feasibility of using recycled concrete aggregates for half-warm mix asphalt. Mater. Struct. (51)81: 1-13. https://doi.org/10.1617/s11527-018-1212-1

[9] M. Wasilewska, D. Małaszkiewicz, and N. Ignatiuk, 2017. Evaluation of Different Mineral Filler Aggregates for Asphalt Mixtures. , in IOP Conf. Series: Materials Science and Engineering, 245. https://doi.org/10.1088/1757$899 X / 245 / 2 / 022042$

[10] P. E. Sebaaly, D. N. Little, and J. A. Epps, 2006. The Benefits of Hydrated Lime in Hot Mix Asphalt. National Lime Association. 
[11] A. Bahia, H, Wang, H, Al-Qadi, I, and Faheem, 2011. Research Characteristics on asphalt mastic and mixture rutting potential. J. Mater. Civ. Eng. https://doi.org/10.3141/2208-05

[12] A. R. Pasandín and I. Pérez, 2015. The influence of the mineral filler on the adhesion between aggregates and bitumen. Int. J. Adhes. Adhes. (58): 53-58. https://doi.org/10.1016/j.ijadhadh.2015.01.005

[13] R. Gubler, Y. Liu, D. A. Anderson, and M. N. Partl, 1999. Investigation of the system filler and asphalt binders by rheological means. J. Assoc. Asph. Paving Technol. (68): 284-304.

[14] R. M. Recasens, A. Martinez, F. P. Jimenez, and H. Bianchetto, 2005. Effect of filler on the aging potential of asphalt mixtures. Transp. Res. Rec. J. Transp. Res. Board (1901): 10-17. https://doi.org/10.1177/0361198105190100102

[15] W. Grabowski and J. Wilanowicz, 2008. The structure of mineral fillers and their stiffening properties in filler-bitumen mastics. Mater. Struct. (44): 793-804. https://doi.org/10.1617/s11527-007-9283-4

[16] P. S. Kandhal and F. Parker, 1998. Aggregate Tests Related to Asphalt Concrete Performance in Pavements. .

[17] M. Chen, J. Lin, and S. Wu, 2011. Potential of recycled fine aggregates powder as filler in asphalt mixture. Construction Build. Mater. (25)3909-3914: https://doi.org/10.1016/j.conbuildmat.2011.04.022

[18] R. Melotti, E. Santagata, M. Bassani, M. Salvo, and S. Rizzo, 2013. A preliminary investigation into the physical and chemical properties of biomass ashes used as aggregate fillers for bituminous mixtures. Waste Manag. (33): 19061917. https://doi.org/10.1016/j.wasman.2013.05.015

[19] B. Huang, X. Shu, and X. Chen, 2007. Effects of mineral fillers on hot-mix asphalt laboratory-measured properties. Int. J. Pavement Eng. (8)1: 1-9. https://doi.org/10.1080/10298430600819170

[20] C. Zheng, R. Li, L. Zou, D. Lv, and Y. Xu, 2018. Effects of Filler - Bitumen Ratio and Mineral Filler Characteristics on the Low-Temperature Performance of Bitumen Mastics. Materials (Basel). (11)1155: https://doi.org/10.3390/ma11071155

[21] P. J. Chavham and S. D. Bhole, 2014. To study the behaviour of marble powder as supplementary cementitious material in concrete. Int. J. Eng. Res. Appl. (4)4( Version 1): 377-381

[22] A. Rana, P. Kalla, H. Verma, and J. Mohnot, 2016. Recycling of dimensional stone waste in concrete: a review. J. Clean. Prod. (135): 312-331. https://doi.org/10.1016/j.jclepro.2016.06.126

[23] M. S. Kirgiz, 2016. Fresh and hardened properties of green binder concrete containing marble powder and brick powder. Eur. J. Environ. Civ. Eng. (20)1: 64-101. https://doi.org/10.1080/19648189.2016.1246692.

[24] P. S. Singh and R. K. Yadav, 2014. Effect of marble dust on index properties of black cotton soil. Int. J. Eng. Res. Sci. Technol. (3)3: 158-163.

[25] Sabat \& Nanda, 2014. Strength, Swelling and Durability Characteristics of Fly-Lime Stabilized Expansive SoilCeramic dust Mixture. Int. J. Earth Sci. (7)3: 1210-1215.

[26] S. . Khan, 2006. Physical Characteristics of Fine Soil Stabilized with Marble Industry Waste. , in 7TH International Congress on Civil Engineering, 7-10.

[27] G. B. \& R. T. Dhanapandian T, 2009. Utilization of Granite and Marble Sawing powder wastes as Brick Materials. J. Earth Environ. Sci. (4)2: 147-160.

[28] U. O. Uyunoglu, 2003. Investigation of Mechanical Properties of Concrete with Waste Marble Dust under the effect of Freeze-Thaw. , in Turkish 4th Marble Symposium.

[29] L. T. Taspolat, I. Zorluer, and H. Koyuncu, 2006. The Effect of Marble Waste Powder on the Freeze-Thaw in Impermeable Clay Layers. J. Constr. Technol. (2): 11-16.

[30] R. Alyousef, O. Benjeddou, C. Soussi, M. A. Khadimallah, and A. Mustafa Mohamed, 2019. Effects of Incorporation of Marble Powder Obtained by Recycling Waste Sludge and Limestone Powder on Rheology, Compressive Strength, and Durability of Self-Compacting Concrete. Adv. Mater. Sci. Eng. (2019): 4609353. https://doi.org/10.1155/2019/4609353

[31] B. Demirel and K. E. Alyamaç, 2018. 6 - Waste marble powder/dust. , in Woodhead Publishing Series in Civil and Structural Engineering, R. Siddique and P. B. T.-W. and S. C. M. in C. Cachim, Eds. Woodhead Publishing, $181-197$. https://doi.org/10.1016/B978-0-08-102156-9.00006-7

[32] N. T. Seghir, M. Mellas, Ł. Sadowski, A. Krolicka, and A. Zak, 2019. The Utilization of Waste Marble Dust as a Cement Replacement in Air-Cured Mortar. Sustainability (11)2215: 1-14. https://doi.org/10.3390/su11082215

[33] Asphalt Pavement Technology Program, 2010. A review of aggregate and asphalt mixture specific gravity measurements and their impacts on asphalt mix design properties.

[34] KeNHA, 1987. Kenya Road Design Manual: Part III Materials and Pavement Design for new roads. , Nairobi, Kenya.

[35] Asphalt Institute Manual Series No. 2 (MS-2), 2001. Mix Design Methods for Asphalt Concrete and other Hot-Mix Types, 6th ed.: . Lexington KY USA: Asphalt Institute.

[36] J. Munyi, T. Idowu, and V. Okumu, 2020. Performance assessment of bitumen when oil-based waste paint is used as an additive. J. Sustain. Res. Eng. (6)1: 1-10.

[37] N. S. Mashaan, A. H. Ali, M. R. Karim, and M. Abdelaziz, 2014. A Review on Using Crumb Rubber in Reinforcement of Asphalt Pavement. Sci. World J. (2014): 214612. https://doi.org/10.1155/2014/214612

[38] S. Hinıslıŏlu and E. Ağar, 2004. Use of waste high density polyethylene as bitumen modifier in asphalt concrete mix. Mater. Lett. (58)3: 267-271. https://doi.org/10.1016/S0167-577X(03)00458-0

[39] C. R. Jones, H. R. Smith, A. C. Edwards, W. G. Ford, J. Rolt, and A. B. Sterling, 2002. Overseas Road Note 19: A guide to the design of hot mix asphalt in tropical and sub-tropical countries. , Crowthorne, Berkshire, United Kingdom.

[40] BS EN 13043, 2015. Aggregates for bituminous mixtures and surface treatments for roads, airfields and other trafficked areas. British Standards Institution, 1-59. 
[41] BS EN 933-3:2012, 2012. Tests for geometrical properties of aggregates. Determination of particle shape. Flakiness index. British Standards Institution.

[42] BS EN 1097-2:2010, 2010. Tests for mechanical and physical properties of aggregates. Methods for the determination of resistance to fragmentation. British Standards Institution.

[43] BS 812-110:1990, 1990. Testing aggregates. Methods for determination of aggregate crushing value (ACV). British Standards Institution.

[44] BS EN 1426:2015, 2015. Bitumen and bituminous binders. Determination of needle penetration. British Standards Institution.

[45] BS EN 12697-34:2012, 2012. Bituminous mixtures. Test methods for hot mix asphalt. Marshall test. British Standards Institution.

[46] BS EN 12697-8:2018, 2019. Bituminous mixtures. Test methods. Determination of void characteristics of bituminous specimens. British Standards Institution.

[47] L. Sun, 2016. Chapter 13 - Asphalt mix homogeneity. , in Structural Behavior of Asphalt Pavements, L. B. T.-S. B. of A. P. Sun, Ed. Butterworth-Heinemann, 821-921. https://doi.org/10.1016/B978-0-12-849908-5.00013-4

[48] V. S. Shekhawat, B. Nagar, and P. Choudhary, 2017. Use of marble dust as fillers in asphalt pavement. Int. J. Mod. Trends Eng. Res. (4)10: 196-204. https://doi.org/10.21884/IJMTER.2017.4327.BS1OM

[49] BS EN 12697-23:2017, 2017. Bituminous mixtures. Test methods. Determination of the indirect tensile strength of bituminous specimens. British Standards Institution.

[50] R. Hicks, 1991. Moisture Damage in Asphalt Concrete. , in Synthesis of Highway Practice 175, Washington DC: Transporation Research Board, National Research Council Washington.

[51] T. A. Abdel-wahed and N. K. Rashwan, 2016. Application of Cement Dust and OPC as Mineral Filler in the binder Hot Mix Asphalt Application of Cement Dust and OPC as Mineral Filler in the binder Hot Mix Asphalt. , in Proceedings of the LJMU 15th Annual International Conference on Asphalt, Pavement Engineering/ and Infrastructure, 15: .

[52] M. J. Choi, Y. J. Kim, H. J. Kim, and J. J. Lee, 2020. Performance evaluation of the use of tire-derived fuel fly ash as mineral filler in hot mix asphalt concrete. J. Traffic Transp. Eng. (English Ed. (7)2: 249-258. https://doi.org/https://doi.org/10.1016/j.jtte.2019.05.004

[53] Lastra-González, P., Lizasoain-Arteaga, E., Castro-Fresno, D. and Flintsch, G., 2021. Analysis of replacing virgin bitumen by plastic waste in asphalt concrete mixtures. International Journal of Pavement Engineering, pp.1-10. 